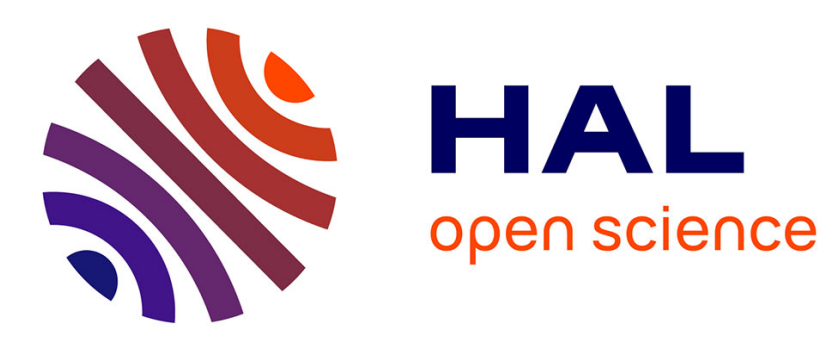

\title{
A Fast Analytic Method to Calculate the Dynamic Response of Railways Sleepers
}

Le Hung Tran, S. Messad, A. Loaec, Denis Duhamel, Gilles Foret, Tien Hoang

\section{To cite this version:}

Le Hung Tran, S. Messad, A. Loaec, Denis Duhamel, Gilles Foret, et al.. A Fast Analytic Method to Calculate the Dynamic Response of Railways Sleepers. Journal of Vibration and Acoustics, 2019, 141 (1), pp.011005. 10.1115/1.4040392 . hal-01978414

\section{HAL Id: hal-01978414 https://hal.science/hal-01978414}

Submitted on 8 Jul 2020

HAL is a multi-disciplinary open access archive for the deposit and dissemination of scientific research documents, whether they are published or not. The documents may come from teaching and research institutions in France or abroad, or from public or private research centers.
L'archive ouverte pluridisciplinaire HAL, est destinée au dépôt et à la diffusion de documents scientifiques de niveau recherche, publiés ou non, émanant des établissements d'enseignement et de recherche français ou étrangers, des laboratoires publics ou privés. 


\section{A fast analytic method to calculate the dynamic response of railways sleepers}

\author{
L-H. Tran* \\ Laboratoire Navier, UMR 8205 \\ École des Ponts, IFSTTAR, CNRS \\ UPE, Champs-sur Marne, France \\ Email: le-hung.tran@enpc.fr
}

\author{
T. Hoang \\ D. Duhamel G. Foret \\ Laboratoire Navier, UMR 8205 \\ École des Ponts, IFSTTAR, CNRS \\ UPE, Champs-sur Marne, France
}

\author{
S. Messad \\ A. Loaec \\ Sateba, Tour Europe \\ 33 places des Corolles \\ 92400 Courbevoie, France
}

Existing analytical models for railway tracks consider only one rail supported by a continuous foundation or periodic concentrated supports (called the periodically supported beam). This article presents an analytical model for a railway track which includes two rails connected by sleepers. By considering the sleepers as Euler-Bernoulli beams resting on a Kelvin-Voigt foundation, we can obtain a dynamic equation for a sleeper subjected to the reaction forces of the rails. Then, by using the relation between the rail forces and displacements from the periodically supported beam model, we can calculate the sleeper responses with the help of Green's function. The numerical applications show that the sleeper is in flexion where the displacement at the middle of the sleeper is greater than those at the rail seats. Moreover, the deformed shape of the sleeper is non-symmetric when the loads on the two rails are different. The model result agrees well with measurements performed using instrumented sleeper in-situ

\section{Nomenclature}

$E_{s} \quad$ Young's modulus of sleeper

$I_{s}$ Cross-sectional moment inertia of sleeper

$\rho_{s} \quad$ Sleeper density

$S_{s} \quad$ Sleeper section area

$w_{s} \quad$ Sleeper displacement in the time domain

$\hat{w}_{s} \quad$ Sleeper displacement in the frequency domain

$\varepsilon_{s} \quad$ Sleeper strain in the time domain

$\hat{\varepsilon}_{s} \quad$ Sleeper strain in the frequency domain

$z_{s} \quad$ Distance to the neutral axis of the sleeper

$T$ Pre-stress of sleeper

$2 L \quad$ Sleeper length

${ }^{*}$ Corresponding author $l \quad$ Sleeper spacing

$k_{r p} \quad$ Stiffness coefficient of the rail pad

$\zeta_{r p}$ Damping coefficient of the rail pad

$k_{p} \quad$ Dynamic stiffness of the rail pad

$k_{f} \quad$ Stiffness coefficient of the ballast

$\zeta_{f}$ Damping coefficient of the ballast

$k_{b} \quad$ Dynamic stiffness of the ballast

$E_{r} \quad$ Young's modulus of rail

$I_{r} \quad$ Cross-sectional moment inertia of rail

$\rho_{r} \quad$ Rail density

$S_{r} \quad$ Rail section area

$w_{j} \quad$ Displacement of rail number $j$ at the sleeper position in the time domain

$\hat{w}_{j} \quad$ Displacement of rail number $j$ at the sleeper position in the frequency domain

$2 a$ Track gauge

$v$ Train speed

$R_{j} \quad$ Force applied due to rail number $j$ on the sleeper in the time domain

$\hat{R}_{j} \quad$ Force applied due to rail number $j$ on the sleeper in the frequency domain

$\mathcal{K}$ Equivalent stiffness

$Q$ Equivalent pre-force

$Q \quad$ Train load

$t$ Time

$\omega$ Angular velocity

$\delta(x-\xi) \quad$ Dirac's function at $x=\xi$

$G(x, \xi) \quad$ Green's function at $x=\xi$

$\partial_{x} \quad$ Partial derivative with regard to $x$ 


\section{Introduction}

Currently, there are many kinds of railway tracks constructed using different technologies. Among many choices of sleeper types, the concrete monoblock sleeper remains popular. Determining the dynamic response of the sleeper is important because it affects the stability of the railway track. Substantial research using analytical methods for rail track have been carried out, for example: the model of a railway track as periodically supported beam [1-10] or the model of an infinite beam placed on a continuous foundation [11-14]), the studies of each track component have been performed on the rail [15-18] or on the ballast $[19,20]$.

The dynamics of the sleepers have been investigated with several different methods. The main objective is to analyse the sleeper behaviour and to model it in the case of different moving charge values. Grassie [21] shows that the uniform beam can be used to model a non-uniform section sleepers. The dynamic lateral resistance of the sleeper has been studied to better understand the interaction zones between the sleeper and the ballast layer [22]. By using experimental and numerical methods, Laryea et al. [23] compared the performance of sleepers made out of different materials. Some works focus on the pre-stressed concrete sleeper using FEM in 2D and in 3D [24, 25].

In this paper, an analytical model for sleepers has been developed by considering a beam resting on a visco-elastic foundation. The dynamic equation of the beam is then written in the frequency domain by using the Fourier transform. When the rails are modeled by periodically supported beams [8], we can write the forces applied by the rails on the sleeper with the help of the Dirac delta function. Then, the dynamic equation for the beam (sleeper) together with the foundation is written and then solved by using the Green's functions. The method of using Green's functions to obtain the response of a beam structure to a moving mass has been successfully applied previously $[26,27]$.

The numerical applications show that the sleeper is in flexion and the dynamic effect when the two rails are charged with different loads. Moreover, the model results have been compared to measurement results in situ, with good agreement. This method is a simple and fast way to approach the dynamic response of sleepers.

\section{Formulations}

Consider a railway track as shown in Fig.1. In this track, a sleeper together with the ballast and foundation are modeled by an Euler-Bernoulli beam resting on a Kelvin-Voigt foundation. The sleeper is subjected to two forces $R_{1}(t)$ and $R_{2}(t)$ from the two rails via the rail pads which are considered as dampers and springs. The total force applied due to the rails on the sleeper can be written with the help of Dirac's functions as follows:

$$
F(x, t)=-R_{1}(t) \delta(x-a)-R_{2}(t) \delta(x+a)
$$

where $2 a$ is the distance between the two rails.

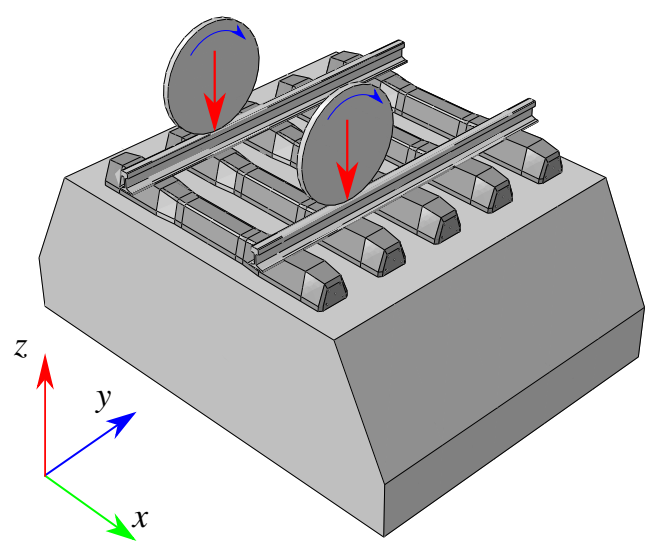

(a)

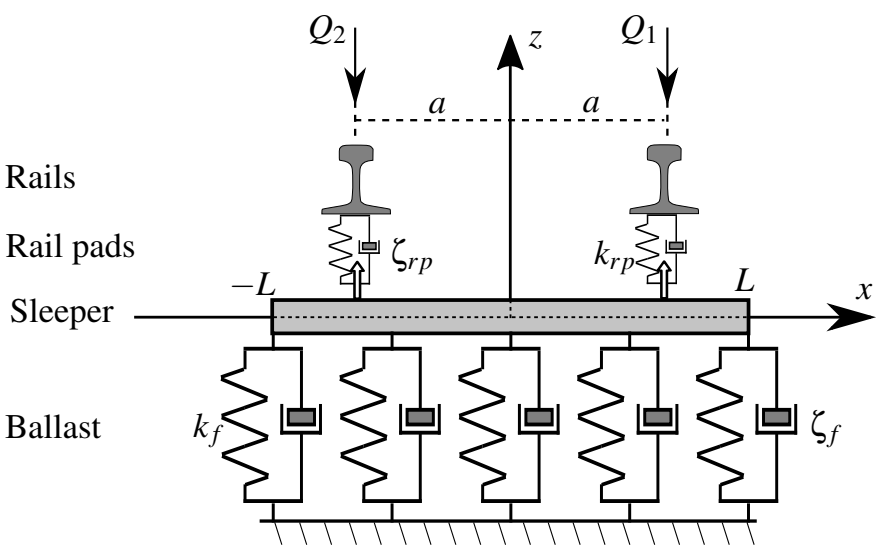

(b)

Fig. 1: Railway track (a) and the analytical model representation (b)

When the rails are modeled by periodically supported beams [8], the forces $R_{1}$ and $R_{2}$ in the frequency domain can be calculated as follows (see Appendix A)

$$
\begin{aligned}
& \hat{R}_{1}(\omega)=\mathcal{K} \hat{w}_{1}(\omega)+Q_{1}(\omega) \\
& \hat{R}_{2}(\omega)=\mathcal{K} \hat{w}_{2}(\omega)+Q_{2}(\omega)
\end{aligned}
$$

where $\mathcal{K}$ is the equivalent stiffness, $Q_{1}$ and $Q_{2}$ are the equivalent pre-forces for the two rails calculated by equation (13) in Appendix A; $w_{1}$ and $w_{2}$ are the rail 1 and 2 displacements at the sleeper position.

Let $w_{s}(x, t)$ be the sleeper displacement at the coordinate $x$ with $-L \leq x \leq L$ where $x$ is the coordinate a long of the sleeper and $t$ denotes time. In Fig.1, we see that $x= \pm a$ corresponds to the positions of the rail seats. The forces $\hat{R}_{1}$, $\hat{R}_{2}$ can be expressed by the constitutive law of the rail pads in the frequency domain as follows:

$$
\begin{aligned}
& \hat{R}_{1}(\omega)=-k_{p}\left(\hat{w}_{1}(\omega)-\hat{w}_{s}(a, \omega)\right) \\
& \hat{R}_{2}(\omega)=-k_{p}\left(\hat{w}_{2}(\omega)-\hat{w}_{s}(-a, \omega)\right)
\end{aligned}
$$


where $k_{p}=k_{r p}+\mathrm{i} \omega \zeta_{r p}$ is the dynamic stiffness of the rail pad and $k_{r p}, \zeta_{r p}$ are the stiffness and damping coefficient of the rail pads. By substituting equation (2) into equation (3), we obtain:

$$
\begin{aligned}
& \hat{R}_{1}(\omega)=\frac{k_{p} \mathcal{K}}{k_{p}+\mathcal{K}} \hat{w}_{s}(a, \omega)+\frac{k_{p}}{k_{p}+\mathcal{K}} Q_{1}(\omega) \\
& \hat{R}_{2}(\omega)=\frac{k_{p} \mathcal{K}}{k_{p}+\mathcal{K}} \hat{w}_{s}(-a, \omega)+\frac{k_{p}}{k_{p}+\mathcal{K}} Q_{2}(\omega)
\end{aligned}
$$

The sleeper displacement $w_{s}(x, t)$ under a force $F(x, t)$ is driven by the dynamic equation of the Euler-Bernoulli beam as follows:

$$
\begin{aligned}
E_{s} I_{s} \frac{\partial^{4} w_{s}(x, t)}{\partial x^{4}}+\rho_{s} S_{s} \frac{\partial^{2} w_{s}(x, t)}{\partial t^{2}}- & T \frac{\partial^{2} w_{s}(x, t)}{\partial x^{2}}+k_{f} w_{s}(x, t) \\
& +\zeta_{f} \frac{\partial w_{s}(x, t)}{\partial t}=F(x, t)
\end{aligned}
$$

where $\rho_{s}, E_{s}, S_{s}$ and $I_{s}$ are the density, the Young's modulus, the section and the cross-sectional moment inertia of the sleeper respectively; $k_{f}$ and $\zeta_{f}$ are the stiffness and damping coefficient of the foundation and $T$ is the sleeper pre-stress.

By combining equations (1) and (5) then by performing a Fourier transform, we obtain:

$$
\begin{array}{r}
\partial_{x}^{4} \hat{w}_{s}(x, \omega)-\frac{T}{E_{s} I_{s}} \partial_{x}^{2} \hat{w}_{s}(x, \omega)-\frac{\rho_{s} S_{s} \omega^{2}-k_{b}}{E_{s} I_{s}} \hat{w}_{s}(x, \omega)= \\
-\frac{\hat{R}_{1}}{E_{S} I_{s}} \delta(x-a)-\frac{\hat{R}_{2}}{E_{s} I_{s}} \delta(x+a)
\end{array}
$$

where $\partial_{x}$ stands for the partial derivative with regard to $x$, $k_{b}=k_{f}+\mathrm{i} \omega \zeta_{f}$ is the dynamic stiffness of the foundation.

Equations (4) and (6) describe the sleeper response. In order to solve these equations, we will use the Green's function of equation (6) defined by:

$$
\frac{\partial^{4} G(x, a)}{\partial x^{4}}-\alpha_{s}^{2} \frac{\partial^{2} G(x, a)}{\partial x^{2}}-\lambda_{s}^{4} G(x, a)=\delta(x-a)
$$

where $\alpha_{s}=\sqrt{\frac{T}{E_{s} I_{s}}}$ and $\lambda_{s}=\sqrt[4]{\frac{\rho_{s} S_{s} \omega^{2}-k_{b}}{E_{s} I_{s}}}$. This is a 4th-order linear differential equation and its Green's function [28] can be written as follows:

$$
G(x, a)=\left\{\begin{array}{l}
A_{1} \mathrm{e}^{\lambda_{1} x}+A_{2} \mathrm{e}^{\lambda_{2} x}+A_{3} \mathrm{e}^{\lambda_{3} x}+A_{4} \mathrm{e}^{\lambda_{4} x} \text { for } x \in[-L, a] \\
B_{1} \mathrm{e}^{\lambda_{1} x}+B_{2} \mathrm{e}^{\lambda_{2} x}+B_{3} \mathrm{e}^{\lambda_{3} x}+B_{4} \mathrm{e}^{\lambda_{4} x} \text { for } x \in[a, L]
\end{array}\right.
$$

where $2 L$ is the beam length, $A_{i}, B_{i}$, and $\lambda_{i}$ (with $1 \leq i \leq$ 4) are parameters to be determined. By using the boundary conditions of the free-free beam, we can obtain the analytical expressions for $A_{i}, B_{i}$ as shown in Appendix B.

The solution of equation (6) can be written with the help of the Green's function as follows:

$$
\hat{w}_{s}(x, \omega)=\frac{-\hat{R}_{1}}{E_{s} I_{s}} G(x, a)+\frac{-\hat{R}_{2}}{E_{s} I_{s}} G(x,-a)
$$

By substituting $x=a$ and $x=-a$ into the aforementioned equation, we obtain respectively:

$$
\begin{aligned}
& \hat{w}_{s}(a, \omega)=\frac{-\hat{R}_{1}}{E_{S} I_{S}} G(a, a)+\frac{-\hat{R}_{2}}{E_{S} I_{S}} G(a,-a) \\
& \hat{w}_{s}(-a, \omega)=\frac{-\hat{R}_{1}}{E_{S} I_{S}} G(-a, a)+\frac{-\hat{R}_{2}}{E_{S} I_{S}} G(-a,-a)
\end{aligned}
$$

By combining equations (4) and (10), we obtain:

$$
\begin{aligned}
& \hat{R}_{1}=\frac{E_{s} I_{s}}{\mathcal{K}} \frac{Q_{1}[G(-a,-a)+\chi]-Q_{2} G(a,-a)}{[\chi+G(a, a)][\chi+G(-a,-a)]-G(-a, a) G(a,-a)} \\
& \hat{R}_{2}=\frac{E_{s} I_{s}}{\mathcal{K}} \frac{Q_{2}[G(a, a)+\chi]-Q_{1} G(-a, a)}{[\chi+G(a, a)][\chi+G(-a,-a)]-G(-a, a) G(a,-a)}
\end{aligned}
$$

where $\chi=E_{s} I_{s} \frac{k_{p}+\mathcal{K}}{k_{p} \mathcal{K}}$.

Equation (11) defines the reaction force of the sleeper on the two rails. Then, the sleeper displacement in the frequency domain can be obtained by replacing $\hat{R}_{1}$ and $\hat{R}_{2}$ in equation (9). By using the inverse Fourier transform, we can get the sleeper response in the time domain.

\section{Applications}

\subsection{The sleeper response under a static load}

Consider a railway track with parameters given in Tab.1. The sleeper response is calculated for two cases: the same loads on the two rails $\left(Q_{1}=Q_{2}=125 \mathrm{kN}\right)$ and different loads $\left(Q_{1}=125 \mathrm{kN}, Q_{2}=180 \mathrm{kN}\right)$ on each rail.

Fig.2 shows the sleeper deformed shapes in the two cases. When the loads are the same, the deformation of the sleeper is symmetric and the rail displacements are the same. When the two loads on the two rails are different, the rail displacements are not the same and it leads to leveling (which a] has a value of $0.23 \mathrm{~mm}$ in this example).

The reaction forces $\hat{R}_{1}$ and $\hat{R}_{2}$ are calculated by equation (11) and Fig.3 shows the forces in the time domain. We see that the reaction forces at the rail seat $\hat{R}_{1}$ and $\hat{R}_{2}$ are equal when the two rails are subjected to the same loads. When the two loads are different, the reaction force is higher for the rail subjected to a higher load. 


\begin{tabular}{|c|c|c|c|}
\hline Content & Unit & Notation & Value \\
\hline $\begin{array}{l}\text { Young's modulus } \\
\text { of rail }\end{array}$ & $\mathrm{GPa}$ & $E_{r}$ & 210 \\
\hline $\begin{array}{l}\text { Cross-sectional moment } \\
\text { inertia of rail }\end{array}$ & $\mathrm{m}^{4}$ & $I_{r}$ & 4.32E-04 \\
\hline Rail density & $\mathrm{kgm}^{-3}$ & $\rho_{r}$ & 7850 \\
\hline Rail section area & $\mathrm{m}^{2}$ & $S_{r}$ & $7.69 \mathrm{E}-3$ \\
\hline $\begin{array}{l}\text { Young's modulus } \\
\text { of sleeper }\end{array}$ & $\mathrm{GPa}$ & $E_{s}$ & 48 \\
\hline $\begin{array}{l}\text { Cross-sectional moment } \\
\text { inertia of sleeper }\end{array}$ & $\mathrm{m}^{4}$ & $I_{S}$ & $2.09 \mathrm{E}-4$ \\
\hline Density of sleeper & $\mathrm{kgm}^{-3}$ & $\rho_{s}$ & 2475 \\
\hline Sleeper section area & $\mathrm{m}^{2}$ & $S_{r}$ & $54.9 \mathrm{E}-3$ \\
\hline Length of sleeper & $\mathrm{m}$ & $2 L$ & 2.41 \\
\hline Track gauge & $\mathrm{m}$ & $2 a$ & 1.435 \\
\hline Stiffness of ballast & $\mathrm{MNm}^{-1}$ & $k_{f}$ & 240 \\
\hline $\begin{array}{l}\text { Damping coefficient } \\
\text { of ballast }\end{array}$ & $\mathrm{kNms}^{-1}$ & $\zeta_{f}$ & 58.8 \\
\hline Stiffness of rail pad & $\mathrm{MNm}^{-1}$ & $k_{r p}$ & 192 \\
\hline $\begin{array}{l}\text { Damping coefficient } \\
\text { of rail pad }\end{array}$ & $\mathrm{MNms}^{-1}$ & $\zeta_{r p}$ & 1.97 \\
\hline Train speed & $\mathrm{ms}^{-1}$ & $v$ & 42.5 \\
\hline Pre-stress of sleeper & $\mathrm{kN}$ & $T$ & 300 \\
\hline Sleeper spacing & $\mathrm{m}$ & $l$ & 0.6 \\
\hline
\end{tabular}

Table 1: Parameters of the railway track [8] and [29]

\subsection{Comparison with measurements}

We compare the sleeper responses from the model and the measurements in situ. The measurement has been performed by Sateba at Creil, France, with a sleeper in which are integrated 6 Fibre Bragg Grating sensors (FBG) in the longitudinal direction as shown in Fig.4. These sensors are positioned to correspond to the rail seats and at the middle of the sleeper sections. The sensors measure the strain and temperature of the sleeper during normal traffic. The presented results are recorded on the 11th of January 2017 by the passing of a Corail train which contains a locomotive and 20 wagons with parameters given in Tab.2. The track parameters remain the same as in Tab.1.

By using the Euler-Bernoulli beam theory, the sleeper strain at the sensor position can be calculated from the sleeper displacement as shown in Appendix C. Here, the train load is modeled by a series of identical moving loads $\left(Q_{j}=Q\right)$ which are characterized by the distances to the first

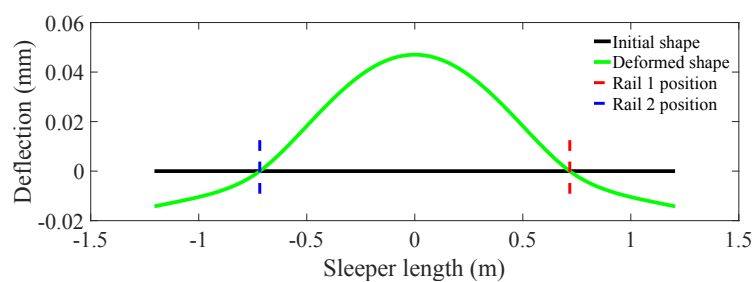

(a) $Q_{1}=Q_{2}=125 \mathrm{kN}$

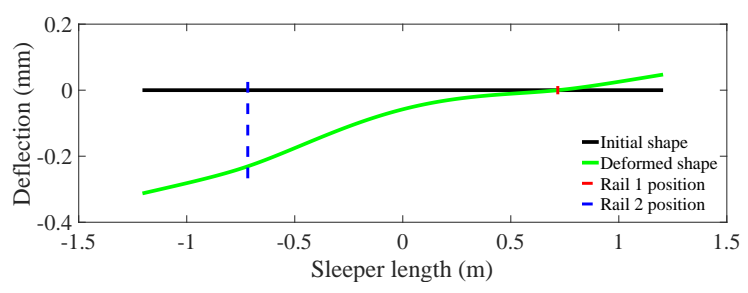

(b) $Q_{1}=125 \mathrm{kN}, Q_{2}=180 \mathrm{kN}$

Fig. 2: Sleeper displacement for the same loads (a) and for different loads (b) on the two rails

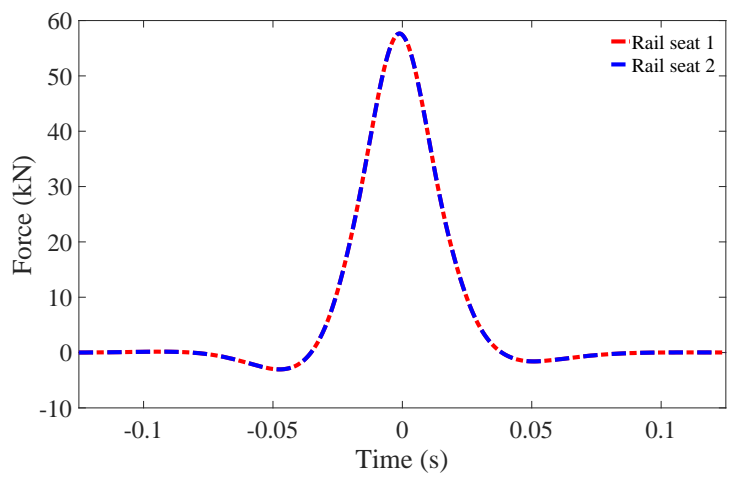

(a) $Q_{1}=Q_{2}=125 \mathrm{kN}$

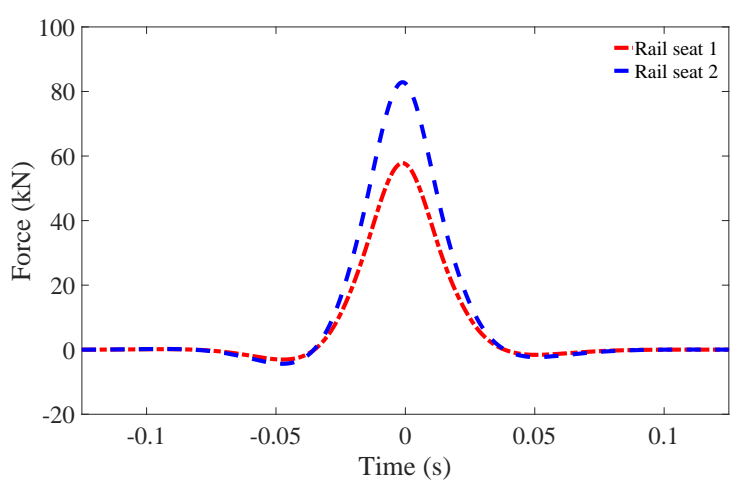

(b) $Q_{1}=125 \mathrm{kN}, Q_{2}=180 \mathrm{kN}$

Fig. 3: Sleeper reaction force for the same loads (a) and for different loads (b) on the two rails

wheel as shown in Fig.5.

Fig.6 shows the sleeper responses predicted by the model and the measured by the sensors. Fig.7 is a zoom of the sleeper responses in a time interval which corresponds to the time for the passing of a wagon bogie. We see that the analytical results agree well with the data. It is remarkable that 


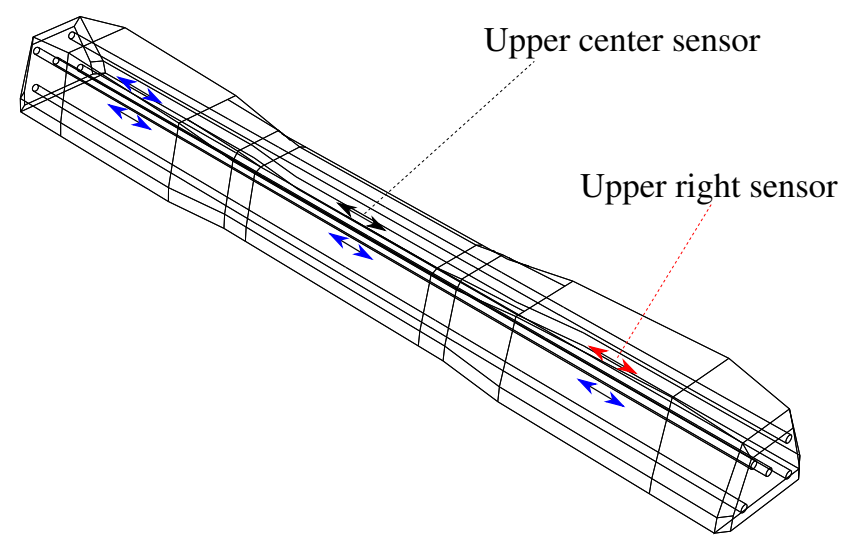

Fig. 4: Instrumented sleeper: upper right sensor (red), and uper center sensor (black)

\begin{tabular}{llcl}
\hline Content & Unit & Notation & Value \\
\hline Locomotive length & $\mathrm{m}$ & $H_{l}$ & 19 \\
Distance of locomotive & $\mathrm{m}$ & $D_{l}$ & 3.2 \\
bogies wheels & & & \\
Distance of locomotive & $\mathrm{m}$ & $d_{l}$ & 10 \\
inner wheels & & & \\
Wagon length & $\mathrm{m}$ & $H_{w}$ & 15.5 \\
Distance of wagon bogie wheels & $\mathrm{m}$ & $D_{w}$ & 2.2 \\
Distance of wagon inner wheels & $\mathrm{m}$ & $d_{w}$ & 9.7 \\
Load per wheel & $\mathrm{kN}$ & $Q$ & 125 \\
Number of wagons & & $n_{w}$ & 20 \\
\hline
\end{tabular}

Table 2: Parameters of the periodic charge

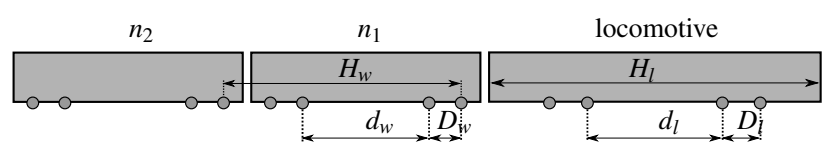

Fig. 5: Diagram of a train showing wheel layout

the sleeper is in compression at the center (positive strain) and in traction at the rail seats (negative strain) which is characteristic of a beam in flexion. Moreover, Fig. 8 presents the responses in the frequency domain. We see that most of the peaks have the same frequency, corresponding to that of the wheels passing.

\section{Conclusions}

In this study, an analytical model for the dynamics of railway sleepers has been developed by considering a model of abeam on Kelvin Voigt foundation. By using the relation between the reaction force and displacement of the rail form the periodically supported beam, the sleeper response cal-

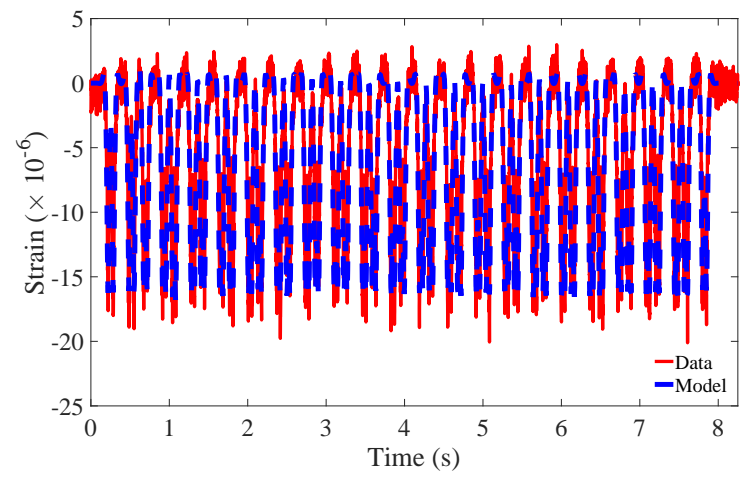

(a) Upper right sensor

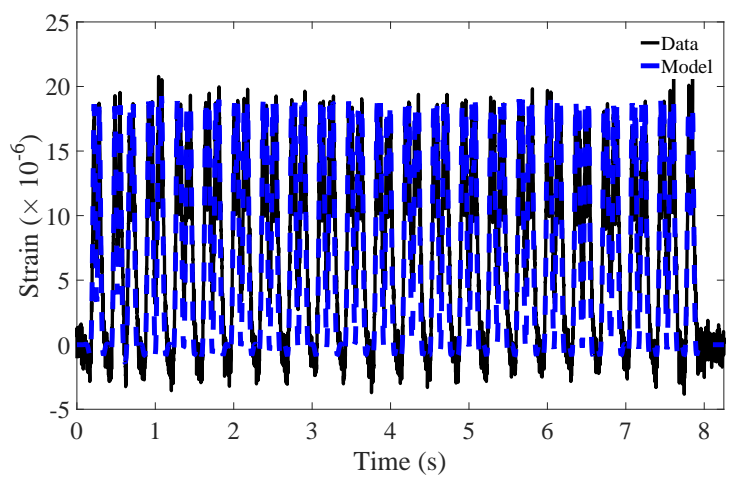

(b) Upper center sensor

Fig. 6: Sleeper response under the passing of a train

culated using the Green's function. This model permits us to calculate fast the sleeper response and it is validated by comparison with in-situ measurements. In future work, this model can be used for inverse problem to determine the track parameters from the sleeper response.

\section{Acknowledgements}

This work has been developed in the context of a partnership between Sateba (Consolis Group) and Ecole des Ponts ParisTech. The authors would like to thank the personnel of Sateba for their support.

\section{References}

[1] Mead, D., 1970. "Free wave propagation in periodically supported, infinite beams". Journal of Sound and Vibration, 11(2), feb, pp. 181-197.

[2] Mead, D., and Yaman, Y., 1991. "The response of infinite periodic beams to point harmonic forces: A flexural wave analysis". Journal of Sound and Vibration, 144(3), pp. 507-529.

[3] Mead, D., 1996. "Wave propagation in continuous periodic structures : Research contributions from Southampton, 1964-1995". Journal of Sound and Vibration, 190(3), pp. 495-524.

[4] Metrikine, A., and Popp, K., 1999. "Vibration of a periodically supported beam on an elastic half-space". 


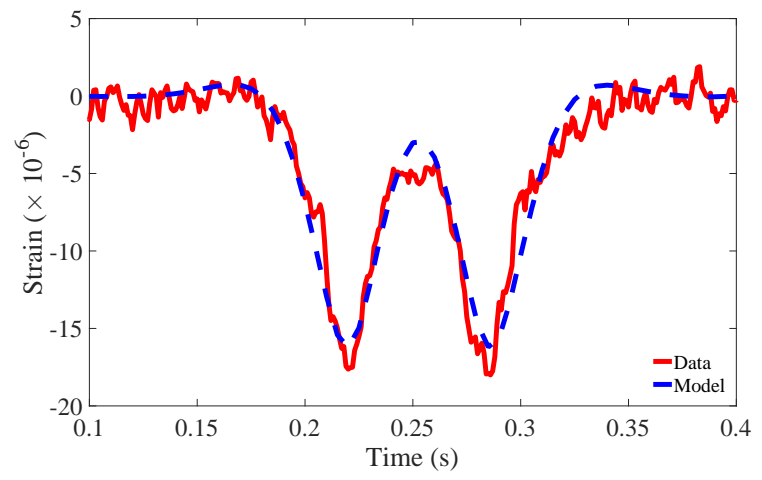

(a) Upper right sensor

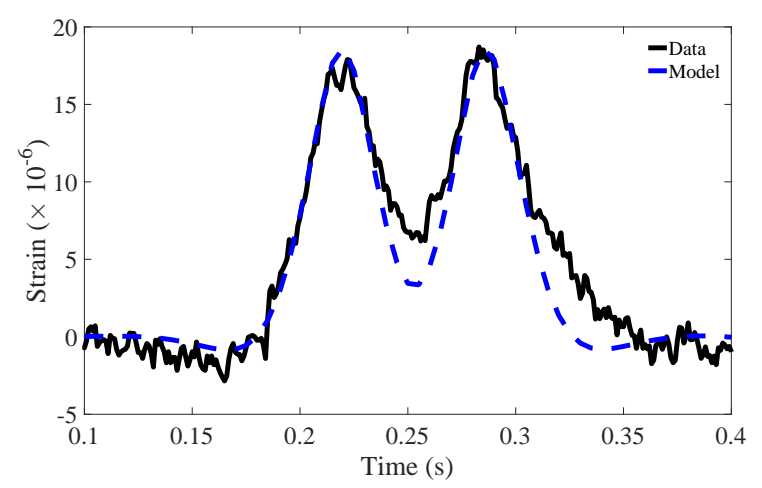

(b) Upper center sensor

Fig. 7: Strain in passing of a wagon boogie

European Journal of Mechanics - A/Solids, 18(4), jul, pp. 679-701.

[5] Vostroukhov, A., and Metrikine, A., 2003. "Periodically supported beam on a visco-elastic layer as a model for dynamic analysis of a high-speed railway track". International Journal of Solids and Structures, 40(21), oct, pp. 5723-5752.

[6] Sheng, X., Jones, C., and Thompson, D., 2005. "Responses of infinite periodic structures to moving or stationary harmonic loads". Journal of Sound and Vibration, 282(1), pp. 125-149.

[7] Sheng, X., Li, M., Jones, C., and Thompson, D., 2007. "Using the Fourier-series approach to study interactions between moving wheels and a periodically supported rail". Journal of Sound and Vibration, 303(3-5), jun, pp. 873-894.

[8] Hoang, T., Duhamel, D., Foret, G., Yin, H., Joyez, P., and Caby, R., 2017. "Calculation of force distribution for a periodically supported beam subjected to moving loads". Journal of Sound and Vibration, 388, pp. 327338.

[9] Nordborg, A., 1998. "Vertical rail vibrations: parametric exication”. Acustica, 84, pp. 289-300.

[10] Hoang, T., Duhamel, D., Foret, G., Yin, H.-P., and Cumunel, G., 2016. "Response of a periodically supported beam on a nonlinear foundation subjected to moving loads". Nonlinear Dynamics, 86(2), Oct, pp. 953-961.

[11] Fryba, L., 1972. Vibration of solids and structures un-

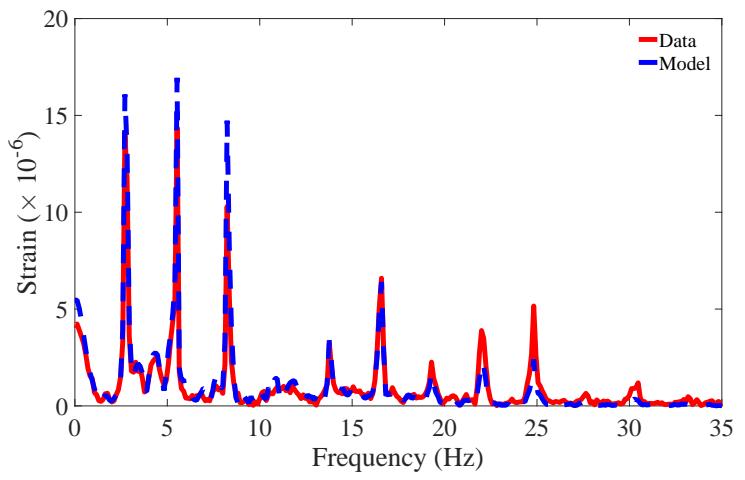

(a) Upper right sensor

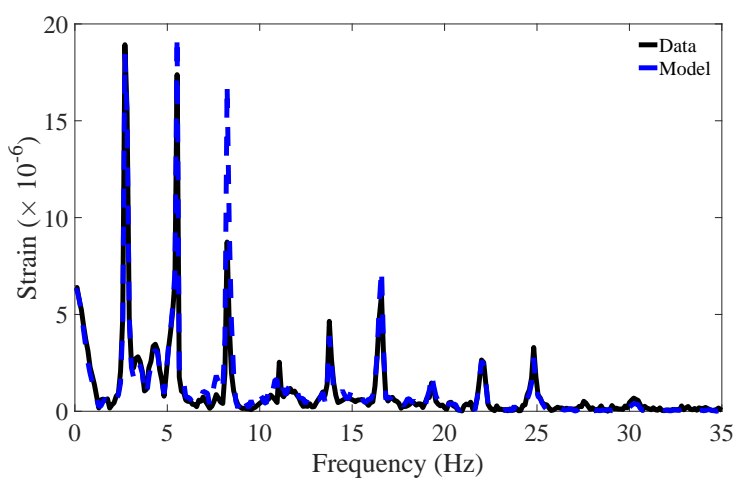

(b) Upper center sensor

Fig. 8: Strain in the frequency domain

der moving load. Thomas Telford.

[12] Nguyen, V.-H., and Duhamel, D., 2006. "Finite element procedures for nonlinear structures in moving coordinates. Part 1: Infinite bar under moving axial loads". Computers \& Structures, 84(21), pp. 13681380 .

[13] Nguyen, V.-H., and Duhamel, D., 2008. "Finite element procedures for nonlinear structures in moving coordinates. Part II: Infinite beam under moving harmonic loads". Computers \& Structures, 86(21), pp. 20562063.

[14] Ding, H., Chen, L.-Q., and Yang, S.-P., 2012. "Convergence of Galerkin truncation for dynamic response of finite beams on nonlinear foundations under a moving load". Journal of Sound and Vibration, 331(10), pp. 2426-2442.

[15] Gavrić, L., 1995. "Computation of propagative waves in free rail using a finite element technique". Journal of Sound and Vibration, 185(3), aug, pp. 531-543.

[16] Thompson, D., 1997. "Experimental analysis of wave propagation in railway tracks". Journal of Sound and Vibration, 203(5), jun, pp. 867-888.

[17] Kostovasilis, D., Thompson, D., and Hussein, M., 2017. "A semi-analytical beam model for the vibration of railway tracks". Journal of Sound and Vibration, 393, pp. 321-337.

[18] Kostovasilis, D., 2017. "Analytical modelling of the vibration of railway track". $\mathrm{PhD}$ thesis, University 
Southampton.

[19] Di Mino, G., Di Liberto, M., Maggiore, C., and Noto, S., 2012. "A Dynamic Model of Ballasted Rail Track with Bituminous Sub-Ballast Layer". Procedia - Social and Behavioral Sciences, 53, oct, pp. 366-378.

[20] Aikawa, A., 2015. "Dynamic characterisation of a ballast layer subject to traffic impact loads using three-dimensional sensing stones and a special sensing sleeper". Construction and Building Materials, 92 , pp. 23-30.

[21] Grassie, S., 1995. "Dynamic modelling of concrete railway sleepers". Journal of Sound and Vibration, 187(5), nov, pp. 799-813.

[22] Esmaeili, M., Hosseini, S., and Sharavi, M., 2016. "Experimental assessment of dynamic lateral resistance of railway concrete sleeper". Soil Dynamics and Earthquake Engineering, 82, pp. 40-54.

[23] Laryea, S., Safari Baghsorkhi, M., Ferellec, J.-F., McDowell, G., and Chen, C., 2014. "Comparison of performance of concrete and steel sleepers using experimental and discrete element methods". Transportation Geotechnics, 1(4), pp. 225-240.

[24] Kumaran, G., Menon, D., and Krishnan Nair, K., 2003. "Dynamic studies of railtrack sleepers in a track structure system". Journal of Sound and Vibration, 268(3), pp. 485-501.

[25] Arab, A. A., Badie, S. S., and Manzari, M. T., 2011. "A methodological approach for finite element modeling of pretensioned concrete members at the release of pretensioning”. Engineering Structures, 33(6), pp. 1918 1929.

[26] Mohamad, A., 1994. “Tables of Green's functions for the theory of beam vibrations with general intermediate appendages". International Journal of Solids and Structures, 31(2), 1, pp. 257-268.

[27] Foda, M., and Abduljabbar, Z., 1998. "A dynamic Green function formulation for the response of a beam structure to a moving mass". Journal of Sound and Vibration, 210(3), pp. 295-306.

[28] Zauderer, E., 1989. Partial differential equations of applied mathematics. John Wiley Sons.

[29] Azoh, T. S., Nzie, W., Djeumako, B., and Fotsing, B. S., 2014. "Modeling of train track vibrations for maintenance perspectives: application". European Scientific Journal, 10(21), pp. 260-275.

[30] Roach, G. F., 1992. Green's Functions, second ed. Cambridge University Press.

[31] Stakgold, I., 1979. Green's functions and boundary value problems. Pure and applied mathematics. Wiley.

\section{Appendix A: Model of a periodically supported beam}

When each rail is modeled by an infinite beam and the sleeper reaction as concentrated forces, we have a system as shown in Fig.9. Each rail is subjected to moving loads $Q_{j}$ which are characterized by their initial positions $D_{j}$ and speed $v$. This analytical model has been developed in the 1970s [1] and is called a periodically supported beam sub-

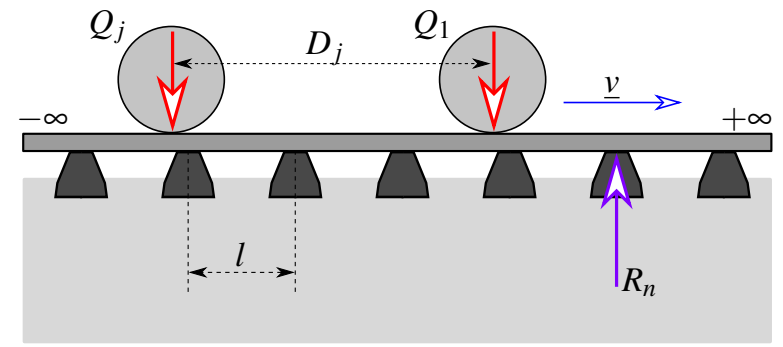

Fig. 9: Periodically supported beam subjected to moving loads

jected to moving forces. Recently, Hoang et al. [8] have proven a relation in the frequency domain between the beam displacement $\hat{w}_{r}(\omega)$ at the sleeper position and the sleeper reaction force $\hat{R}_{r}(\omega)$ which holds for any type of sleepers and foundation:

$$
\hat{R}(\omega)=\mathcal{K}(\omega) \hat{w}_{r}(\omega)+Q(\omega)
$$

where $\mathcal{K}(\omega)$ and $Q(\omega)$ are the so-called equivalent stiffness and pre-force of the periodically supported beam. By taking the case of an Euler-Bernoulli beam for the rail, the expression for $\mathcal{K}(\omega)$ and $Q(\omega)$ is given by:

$$
\begin{aligned}
& \mathcal{K}(\omega)=4 \lambda_{r}^{3} E_{r} I_{r}\left[\frac{\sin l \lambda_{r}}{\cos l \lambda_{r}-\cos \frac{\omega l}{v}}-\frac{\sinh l \lambda_{r}}{\cosh l \lambda_{r}-\cos \frac{\omega l}{v}}\right]_{(13}^{-1} \\
& Q(\omega)=\frac{\mathcal{K}(\omega)}{v E_{r} I_{r}\left[\left(\frac{\omega}{v}\right)^{4}-\lambda_{r}^{4}\right]} \sum_{j=1}^{K} Q_{j} \mathrm{e}^{-\mathrm{i} \omega \frac{D_{j}}{v}}
\end{aligned}
$$

where $\lambda_{r}=\sqrt[4]{\frac{\rho_{r} S_{r} \omega^{2}}{E_{r} I_{r}}}$. The parameters $\rho_{r}, E_{r}, S_{r}$ and $I_{r}$ are the density, Young's modulus, section and the cross-sectional inertia of the rail respectively.

\section{Appendix B: Calculation of the Green's function} [28]:

The characteristic function of equation (7) is given by

$$
\mathcal{P}(\lambda)=\lambda^{4}-\alpha_{s}^{2} \lambda^{2}-\lambda_{s}^{4}
$$

This function has 4 complex roots $\lambda_{i}(i=1,2,3,4)$ which are defined as $\lambda_{1,2}^{2}=\frac{\alpha_{s}^{2}+\sqrt{\alpha_{s}^{4}+4 \lambda_{s}^{4}}}{2}$ and $\lambda_{3,4}^{2}=$ $\frac{\alpha_{s}^{2}-\sqrt{\alpha_{s}^{4}+4 \lambda_{s}^{4}}}{2}$. The general form of the Green's function is given by:

$$
G(x, a)= \begin{cases}A_{1} \mathrm{e}^{\lambda_{1} x}+A_{2} \mathrm{e}^{\lambda_{2} x}+A_{3} \mathrm{e}^{\lambda_{3} x}+A_{4} \mathrm{e}^{\lambda_{4} x} & \text { for } x \in[-L, a] \\ B_{1} \mathrm{e}^{\lambda_{1} x}+B_{2} \mathrm{e}^{\lambda_{2} x}+B_{3} \mathrm{e}^{\lambda_{3} x}+B_{4} \mathrm{e}^{\lambda_{4} x} & \text { for } x \in[a, L]\end{cases}
$$


In addition, the Green's function has to satisfy the boundary condition of the free-free beam and the continuity at $x=a$. Thus, the eight constants $A_{i}(\omega)$ and $B_{i}(\omega)$ with $1 \leq i \leq 4$, are evaluated such that the Green's function $G(x, a)$ satisfies the following conditions [30] [31]:

1. Two boudary conditions at each end of the beam depending on the type of the end support, for a free-free beam:

$$
\begin{aligned}
& \partial_{x}^{2} G(-L, a)=\partial_{x}^{2} G(L, a)=0 \\
& \partial_{x}^{3} G(-L, a)=\partial_{x}^{3} G(L, a)=0
\end{aligned}
$$

2. Continuity conditions of displacement, slope and moment at $x=a$ :

$$
\begin{aligned}
& G\left(a^{+}, a\right)-G\left(a^{-}, a\right)=0 \\
& \partial_{x} G\left(a^{+}, a\right)-\partial_{x} G\left(a^{-}, a\right)=0 \\
& \partial_{x}^{2} G\left(a^{+}, a\right)-\partial_{x}^{2} G\left(a^{-}, a\right)=0
\end{aligned}
$$

3. Shear force discontinuity of magnitude one at $x=a$ :

$$
\partial_{x}^{3} G\left(a^{+}, a\right)-\partial_{x}^{3} G\left(a^{-}, a\right)=1
$$

By equation (15), we obtain:

$$
\begin{array}{ll}
\lambda_{1}^{2} A_{1} \mathrm{e}^{-\lambda_{1} L}+\lambda_{2}^{2} A_{2} \mathrm{e}^{-\lambda_{2} L}+\lambda_{3}^{2} A_{3} \mathrm{e}^{-\lambda_{3} L}+\lambda_{4}^{2} A_{4} \mathrm{e}^{-\lambda_{4} L} & =0 \\
\lambda_{1}^{3} A_{1} \mathrm{e}^{-\lambda_{1} L}+\lambda_{2}^{3} A_{2} \mathrm{e}^{-\lambda_{2} L}+\lambda_{3}^{3} A_{3} \mathrm{e}^{-\lambda_{3} L}+\lambda_{4}^{3} A_{4} \mathrm{e}^{-\lambda_{4} L} & =0 \\
\lambda_{1}^{2} B_{1} \mathrm{e}^{\lambda_{1} L}+\lambda_{2}^{2} B_{2} \mathrm{e}^{\lambda_{2} L}+\lambda_{3}^{2} B_{3} \mathrm{e}^{\lambda_{3} L}+\lambda_{4}^{2} B_{4} \mathrm{e}^{\lambda_{4} L} & =0 \\
\lambda_{1}^{3} B_{1} \mathrm{e}^{\lambda_{1} L}+\lambda_{2}^{3} B_{2} \mathrm{e}^{\lambda_{2} L}+\lambda_{3}^{3} B_{3} \mathrm{e}^{\lambda_{3} L}+\lambda_{4}^{3} B_{4} \mathrm{e}^{\lambda_{4} L} & =0 \\
\left(B_{1}-A_{1}\right) \mathrm{e}^{\lambda_{1} a}+\left(B_{2}-A_{2}\right) \mathrm{e}^{\lambda_{2} a} & \\
+\left(B_{3}-A_{3}\right) \mathrm{e}^{\lambda_{3} a}+\left(B_{4}-A_{4}\right) \mathrm{e}^{\lambda_{4} a} & =0 \\
\lambda_{1}\left(B_{1}-A_{1}\right) \mathrm{e}^{\lambda_{1} a}+\lambda_{2}\left(B_{2}-A_{2}\right) \mathrm{e}^{\lambda_{2} a} & \\
+\lambda_{3}\left(B_{3}-A_{3}\right) \mathrm{e}^{\lambda_{3} a}+\lambda_{4}\left(B_{4}-A_{4}\right) \mathrm{e}^{\lambda_{4} a} & =0 \\
\lambda_{1}^{2}\left(B_{1}-A_{1}\right) \mathrm{e}^{\lambda_{1} a}+\lambda_{2}^{2}\left(B_{2}-A_{2}\right) \mathrm{e}^{\lambda_{2} a} & \\
+\lambda_{3}^{2}\left(B_{3}-A_{3}\right) \mathrm{e}^{\lambda_{3} a}+\lambda_{4}^{2}\left(B_{4}-A_{4}\right) \mathrm{e}^{\lambda_{4} a} & =0 \\
\lambda_{1}^{3}\left(B_{1}-A_{1}\right) \mathrm{e}^{\lambda_{1} a}+\lambda_{2}^{3}\left(B_{2}-A_{2}\right) \mathrm{e}^{\lambda_{2} a} & \\
+\lambda_{3}^{3}\left(B_{3}-A_{3}\right) \mathrm{e}^{\lambda_{3} a}+\lambda_{4}^{3}\left(B_{4}-A_{4}\right) \mathrm{e}^{\lambda_{4} a} & =1
\end{array}
$$

